\title{
TEACHING COURSES ONLINE: HOW MUCH TIME DOES IT TAKE?
}

\author{
Belinda Davis Lazarus
}

Associate Professor of Special Education

University of Michigan-Dearborn

School of Education \#116

4901 Evergreen Road

Dearborn, Michigan 48128

Phone: 1.313.436.9135

Fax: 1.313.593.9961

blazarus@umd.umich.edu

\begin{abstract}
Studies show that temporal factors like workload and lack of release time inhibit faculty participation in developing and teaching online courses; however, few studies exist to gauge the time commitment. This longitudinal case study, presented at the Seventh Annual Sloan-C International Conference on ALN, examined the amount of time needed to teach three asynchronous online courses at The University of Michigan-Dearborn from Winter 1999 through Winter 2000. Twenty-five students were enrolled in each course. Self-monitoring was used to measure the amount of time required to complete the following activities: 1) reading and responding to emails; 2) reading, participating in, and grading 10 online discussions; and 3) grading 15 assignments. Using a stopwatch, the investigator timed and recorded the number of minutes needed for each activity. Also, all messages and assignments were archived and frequency counts were recorded. The weekly, mean number of minutes and assignments was entered on line graphs for analysis. The data showed that teaching each online course required 3 to 7 hours per week, with the greatest number of emails and amount of time required during the first and last 2-weeks of the semesters. Participation in and grading of the discussions took the greatest amount of time and remained steady across the semester. However unlike many live courses, the students participated more in the discussions than the instructor did. The number of assignments that were submitted each week steadily increased over each semester. This case study indicates that the time needed to teach online courses falls within the range of reasonable expectations for teaching either live or online courses and represents the beginning of this area of inquiry. Consequently, additional studies are needed with a variety of instructors across a variety of courses and disciplines to further pinpoint faculty time commitment.
\end{abstract}

\section{KEYWORDS}

Online Courses, Longitudinal Experiment, Faculty Workload, Teaching Online Courses

\section{INTRODUCTION}

For centuries, face-to-face courses have been the norm in post secondary institutions. Indeed, faculty and students' perceptions and pedagogical methods have been based on a longstanding history of courses in which faculty teach students within the confines of four walls for a designated time period. Thus, faculty perceptions of the time commitment needed to teach courses has been guided by time limits including 
faculty determined office hours. However the rapid advent of asynchronous online courses has challenged the parameters of traditional teaching and transformed the learning environment into a timeless entity without walls. The rapid proliferation of online courses and administrative pressure to compete in the market have cast faculty into an oftentimes unfamiliar and uncomfortable realm that engenders questions without apparent answers.

Faculty workload remains a central concern. Several studies show that temporal factors like workload and lack of release time inhibit faculty participation in developing and teaching online courses [1, 2, 3, 4], and instructors often express concerns regarding the amount of time needed to teach online courses. The absence of discrete parameters such as set class time, specific office hours, and controlled student contact lead to speculation about time commitment comparisons to live course experiences. Unfortunately, few studies quantify the amount of time needed to teach live or online courses. And, unlike live courses, the online versions of courses do not clearly indicate time factors. Studies and methodologies are needed to gauge the time needed to teach online courses.

Although numerous, complex factors are associated with teaching online courses (such as course preparation, course level, content, and design, and so on), the present study focuses on the amount of time needed to actually teach the course. In this study, self monitoring was used to measure the amount of time that was needed to teach online, education courses offered at the University of Michigan-Dearborn from Winter 1999 though Winter 2000. The study also looked at trends in student participation. Also, to prepare for the study and to perfect self-monitoring techniques, preliminary work was done on a "test" course that was taught in Fall 1998.

\section{BACKGROUND: COURSE DESCRIPTIONS}

Two courses - one each at the introductory and advanced level - served as direct and systematic focuses, to examine the possible effects of course level on the time needed to teach the courses. Online discussions and assignments are required and graded for each topic that is covered. Students are required to participate in ten topical discussions by initiating a thread and responding to at least one of their classmate's postings. The assignments for each course differ in structure and complexity and are described below.

Teaching the Exceptional Child is an undergraduate, survey-type course that addresses characteristics and accommodations for students with disabilities. The course requires students to gain basic knowledge as a prerequisite for more advanced courses and student teaching. In addition to the discussions, students are required to complete and submit guided notes for each topic in the readings and online lectures. The guided notes are a skeleton outline in textbox forms that students complete as they read the assignment and lecture. Each set of guided notes contains 20-25 blank spaces and requires approximately 200 words to complete. The students' responses are archived and graded in the instructor's online results file.

Assessment of the Learner is an advanced graduate course that addresses multi-disciplinary assessment in special education. Prior knowledge is required about laws governing special education assessment, characteristics of students with mild disabilities, service delivery models, and norm-and-criterion referenced testing. Completion of the course requires knowledge and use of descriptive statistics, analysis of a wide variety of assessment tools, and application and interpretation of assessment data to plan instruction. In addition to participation in the online, discussions, students are required to complete 15 case studies in which information from a variety of sources is used to solve a practical problem. 


\section{RESEARCH QUESTION}

A longitudinal case study approach was used to answer the following research questions:

1. How much time does it take the instructor to send, read and respond to emails, participate in and grade the discussions, and grade assignments each week?

2. How many emails, discussion messages, and assignments are received each week?

3. What is the level and type of student participation in the course across the semester?

\section{METHOD}

\section{A. Setting and Participants}

The investigator, a female Associate Professor of Special Education, served as the instructor of each course used in the study. She had taught previous, live versions of the courses for 14 years and was also the original developer of the live version of the Assessment of the Learner course and had made major revisions to the Teaching the Exceptional Child course. Prior to the study, the instructor participated in two online courses to learn how to design and author WebPages, activities, and assignments for online courses. As a result, the instructor designed, formatted, and authored each course used in the study. The course content and design was based on principles of effective and direct instruction in which skills are taught through demonstrations, guided practice with immediate corrective and reinforcing feedback, and independent practice.

Students in the courses were between 25 and 47 years of age. All of the graduate students were part-time students. Eighty-one percent of the graduate students were full-time teachers, $11 \%$ were substitute teachers, and $8 \%$ were not employed outside the home. Forty-four percent of the undergraduate students were full-time students and $56 \%$ were part-time students.

\begin{tabular}{|l|c|c|c|c|c|}
\hline \multicolumn{1}{|c|}{ Course } & Female & Male & Graduate & Undergraduate & Total \\
\hline EDC 460 & 22 & 3 & 5 & 20 & 25 \\
\hline EDC460 & 22 & 3 & 4 & 21 & 25 \\
\hline EDN503 & 23 & 2 & 25 & 0 & 25 \\
\hline
\end{tabular}

Table 1. Characteristics of students

\section{B. Data Collection}

\section{Identification of Variables}

During the Fall 1998 semester, a pilot study was conducted to identify the variables to measure. The investigator taught one online version of Educating the Exceptional Child and analyzed the course syllabus and the instructor's activities to determine which components of the course required instructor time and produced permanent products such as emails. The investigator also practiced various types of self-monitoring to determine which method provided the most accurate measurement. Three components emerged as measurable variables and functions required to teach the courses: email, discussion, and assignments.

Email. Only emails that were related directly to the course were counted and included: 1) instructor- 
initiated emails to the entire class and individuals with course information, announcements, and performance feedback; 2) student-initiated emails pertaining to individual concerns that required the instructor to read and/or reply; and 3) emails from technicians with questions about the course and/or information about server updates and downtime that affected the courses.

Discussions. Each course included 10, topical discussions, and participation in each online discussion was required. Each discussion lasted for 7 to 10 days and students could participate at any time within the discussion time period. All messages that required the instructor to read, reply to, and/or grade were included in the frequency and duration counts. Student participation was graded according to the following specifications:

Participation. Students were required to initiate at least one new topic per discussion and respond to at least one other person's posting for each weekly discussion. Each contribution had to be substantive, thoughtful, insightful, of quality, and demonstrate that the student had read, analyzed, and evaluated the course material.

Grading. Student contributions to the discussions were graded according to the following criteria that describe the posting:

1) stayed on the topic; 2) initiated a new topic; 3) visited and posted on more than one date; 4) used personal and professional experiences as examples of concepts that $\mathrm{s} / \mathrm{he}$ has already explained in the message, and related those experiences to the topic of the discussion and the assigned material; 5) responded to and extended another classmate's message in a way that carried the concept a step further; 6) discussed concepts related to the topic by describing the concept and providing appropriate examples; and 7) observed proper netiquette.

Assignments. Students were required to complete an assignment for each of 15 topics covered in the courses. The assignments were posted on forms that enable the students to submit their responses to the instructor and immediately receive the correct answers on the form's confirmation form. Consequently, students received immediate feedback and were able to evaluate their performance. The instructor graded assignments each day and posted grades in an online grade book every week.

\section{Data Collection}

During the pilot study, it became apparent that frequency counts and duration recordings were the best methods to collect the data needed to answer the research questions. The frequency counts enabled the investigator to identify the class activity levels by frequency and date. For the frequency counts, all messages, emails, and assignments were dated and archived. All assignments that were submitted for the week were counted in the online file. To count the messages in the discussion, the investigator printed the contents frame and counted all messages. Duplicate messages posted by multiple clicks of the submit button were not included in the frequency count. All student emails and instructor replies were filtered to folders labeled Weeks 1 through 15 and counted each week. All counts were entered onto a data collection sheet.

Duration recording was used to measure the amount of time that the instructor used to: 1) read, send, and reply to emails; 2) read, grade, and participate in the online discussions; and 3) grade assignments. The instructor used a stopwatch to time each separate activity. One hour each morning and evening was scheduled 6 days a week to collect data for a total of 12 hours per week. During each hour, the instructor focused on one activity at a time. For example, the instructor focused on the discussion until all new 
messages were read and graded. The instructor started and stopped the stopwatch at the beginning and end of each activity. The stopwatch was also stopped for any interruption that required the instructor to leave the computer or attend to interruptions. The amount of time needed for each activity was recorded on datasheets each day and totaled for the week.

\section{RESULTS}

\section{A. Data Analysis}

Data were charted on line graphs to depict trends, frequencies, and the amount of time that the instructor spent on each activity. The line graphs also provided a comparison of the amount of time required for each activity.

Figure 1 depicts the frequencies and duration of the teaching activities for the Winter 1999 course. The number of emails addressed each week ranged between 19 and 49 with a mean of 30 . The number of assignments addressed each week ranged between 14 and 38 with a mean of 26 and the number of messages in the discussions ranged between 158 and 207 with a mean of 183 . The number of minutes spent each week on email activities ranged between 24 and 61 with a mean of 41 . Minutes spent participating in and grading the discussions ranged between 172 and 237 minutes per week with a mean of 204 minutes. The number of minutes spent each week grading the assignments ranged between 41 and 114 minutes with a mean of 76 minutes. Overall the total number of minutes required to teach the course ranged between 213 - 337 minutes per week.

The trends and data levels show that the discussions took the greatest amount of time. Responding to emails took the least amount of time. Also, the greatest number of emails were sent and received during the first and last two weeks of the semester, and the submission of assignments gradually increased over the semester.

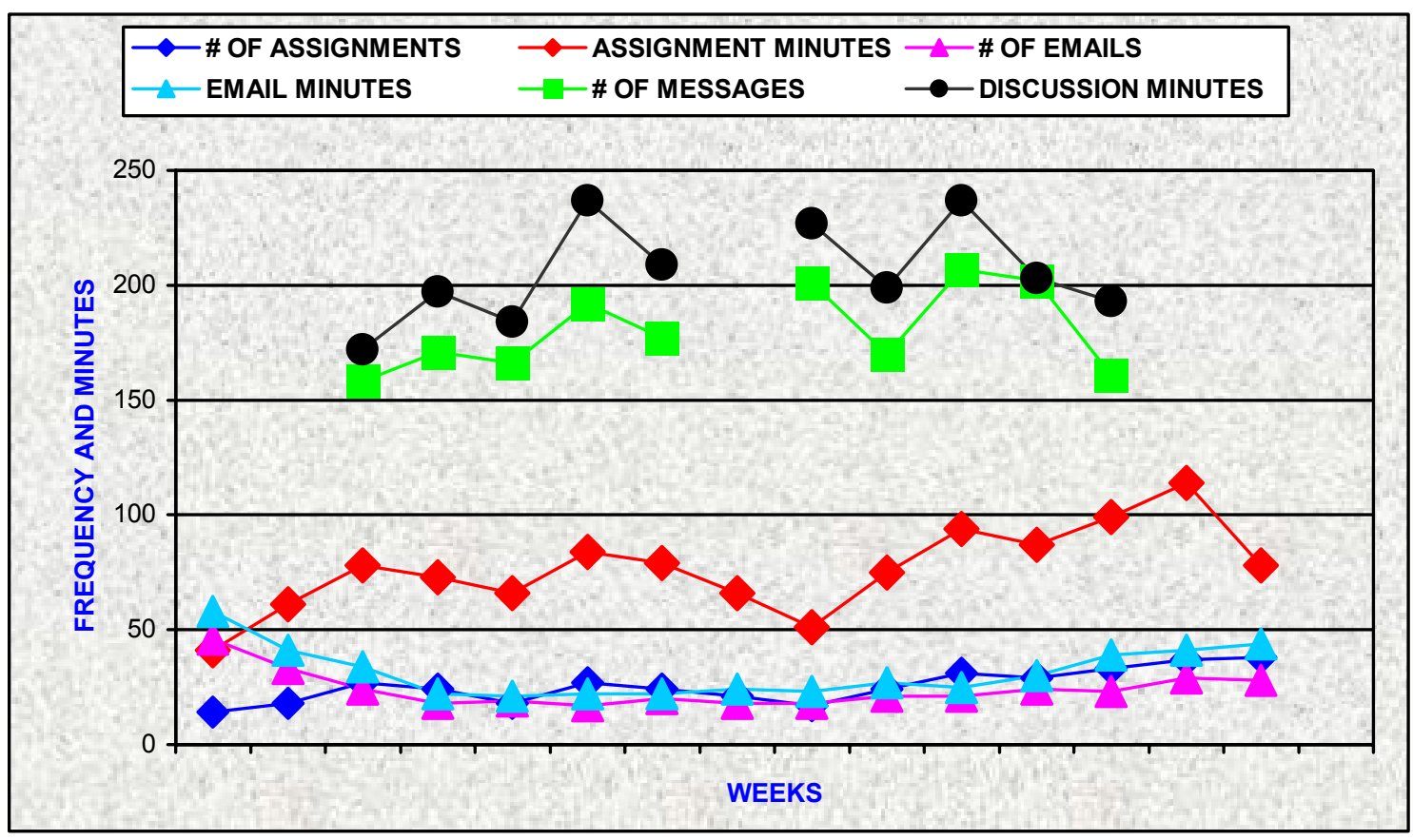

Figure 1. Winter 1999, Teaching the Exceptional Child course. 
The mean number of assignments, emails, and messages submitted each week and the mean number of minutes required to read and grade assignments, postings, and emails.

Figure 2 shows the frequencies and duration of the teaching activities for the Fall 1999 course. The number of emails received and sent each week ranged between 17 and 46 with a mean of 24 . The number of assignments received each week ranged between 18 and 46 with a mean of 31 and the number of messages in the discussions ranged between 157 and 204 with a mean of 179 . The number of minutes spent each week on email activities ranged between 21 and 58 with a mean of 32 . Minutes spent participating in and grading the discussions ranged between 174 and 236 minutes per week with a mean of 204 minutes. The number of minutes spent each week grading the assignments ranged between 51 and 122 minutes with a mean of 80 minutes. Overall the total number of minutes required to teach the course ranged between 229 - 384 minutes per week.

Again the trends and data levels show that the discussions took the greatest amount of time and the emails took the least amount of time. The greatest number of emails were sent and received during the first and last two weeks of the semester and the submission of assignments gradually increased over the semester.

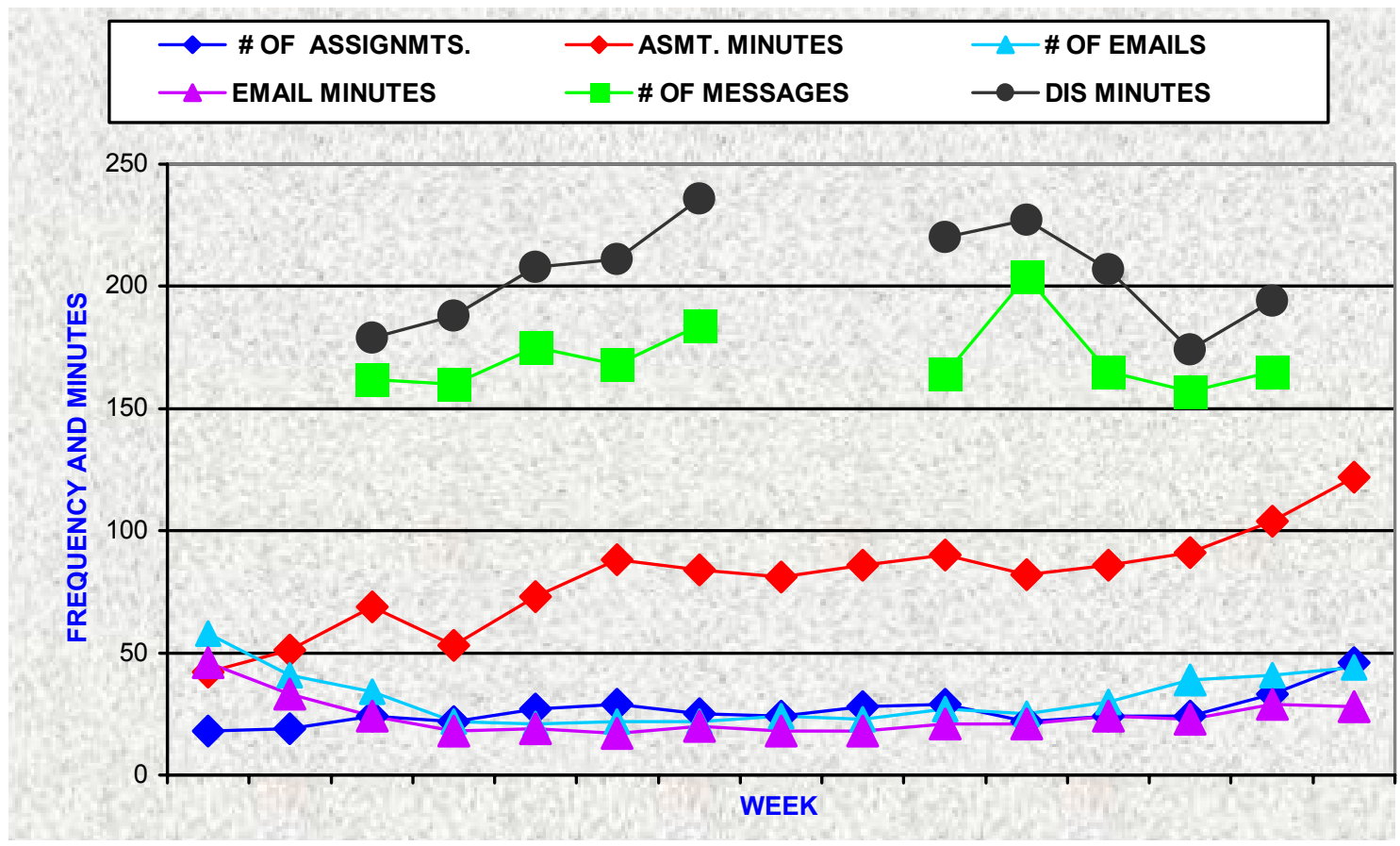

Figure 2. Fall 1999, Teaching the Exceptional Child course.

The mean number of assignments, emails, and messages submitted each week and the mean number of minutes required to read and grade assignments, postings, and emails.

Figure 3 depicts the frequencies and duration of the teaching activities for the Winter 2000 course. The number of emails addressed each week ranged between 14 and 49 with a mean of 27 . The number of assignments addressed each week ranged between 17 and 42 with a mean of 28 and the number of messages in the discussions ranged between 102 and 176 with a mean of 146 . The number of minutes spent each week on email activities ranged between 23 and 66 with a mean of 40 . Minutes spent participating in and grading the discussions ranged between 144 and 257 minutes per week with a mean of 192 minutes. The number of minutes spent each week grading the assignments ranged between 39 and 91 minutes with a mean of 68 minutes. Overall the total number of minutes required to teach the course 
ranged between $206-414$ minutes per week.

Once again, the trends and data levels show that the discussions took the greatest amount of time. Responding to emails took the least amount of time. Also, the greatest number of emails were sent and received during the first and last two weeks of the semester and the submission of assignments gradually increased over the semester.

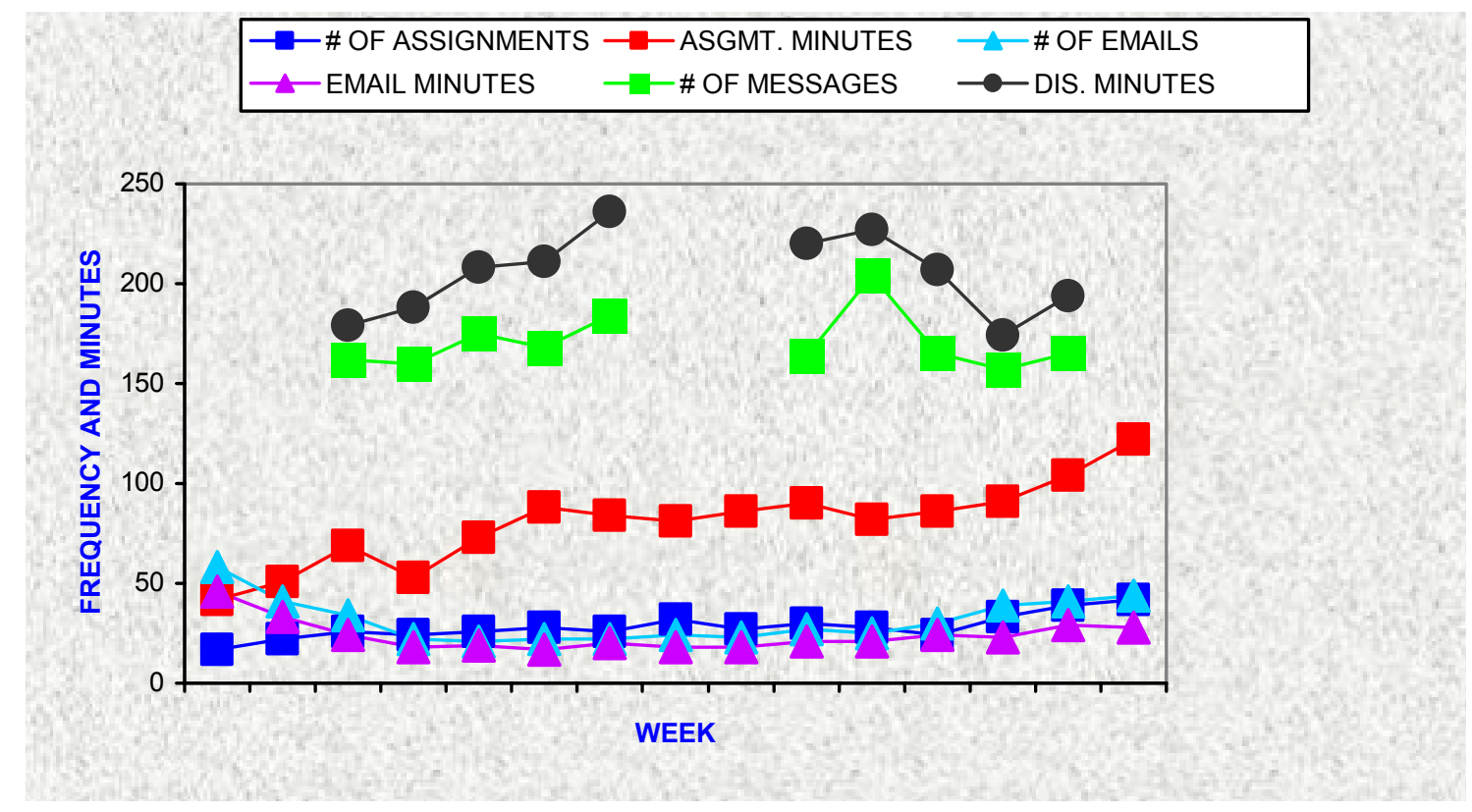

Figure 3. Winter, 2000, Assessment of the Learner course.

The mean number of assignments, emails, and messages submitted each week and the mean number of minutes required to read and grade assignments, postings, and emails.

\section{DISCUSSION AND CONCLUSIONS}

This study attempted to measure the amount of time needed to teach three online courses. The data collected across the three courses were fairly consistent and indicated that teaching courses online requires between $31 / 2$ and 7 hours per week. The graduate level course required $30-45$ minutes per week longer that the introductory courses. However the time commitment is within reasonable expectations, but unlike live courses that meet between 1 and 3 times per week, the instructor needs to be online and available to students each day. Participating in and grading the online discussions takes the greatest amount of time, however, the discussions show that the students posted 4 to 5 times as many messages as the instructor. Consequently, consistent with principles of effective instruction, students had more opportunities to respond and interact in the online courses than in live, lecture-type courses.

The data represent a glimpse at one of the numerous, complex variables that are associated with asynchronous learning. The time needed to teach online courses may vary according to factors such as content area, type and level of course, course design, and a variety of student factors such as graduate and undergraduate levels. Consequently, the study's data may only apply to similar courses taught under similar circumstances. Furthermore, any comparisons between live and online courses are only inferred. The study did not measure the amount of time needed to teach live courses, however the $3 \frac{1}{2}-7$ hours per 
week that were devoted to teaching online seems comparable to the hours of live class time, office hours, and grading needed for live courses.

The present study represents an area of inquiry that includes numerous, complex variables. Additional studies are needed that focus on the time needed to teach a variety of courses in the myriad of disciplines found in higher education. Additional studies are also needed to determine how student characteristics, course design, and course preparation affect faculty workload.

\section{REFERENCES}

1. Schifter, C.C., Faculty Participation in Asynchronous Learning Networks: A Case Study of Motivating and Inhibiting Factors, Journal of Asynchronous Learning, 4(1), June, 2000.

2. Betts, K.S., Factors Influencing Faculty Participation in Distance Education in Postsecondary Education in the United States: An Institutional Study, Ph.D. dissertation, The George Washington University, 1998.

3. Clark, T., Attitudes of Higher Education Faculty toward Distance Education: A National Survey, The American Journal of Distance Education, 7 (2), 19-33, 1993.

4. Taylor, J.C., and White, J.V., Faculty Attitudes towards Teaching in the Distance Education Mode: An Exploratory Investigation, Research in Distance Education, July, 7-11, 1991.

\section{ABOUT THE AUTHOR}

Belinda Davis Lazarus is Associate Professor of Special Education in the School of Education at the University of Michigan-Dearborn. In 1997, Dr. Lazarus designed and taught the University's first online course and master's degree. She earned a B.A. in education and Ph.D. in teacher education and applied behavior analysis at the Ohio State University and an M.Ed. in special education and administration at Bowling Green State University. 